\title{
Changes in Lung Diffusing Capacity of Elite Artistic Swimmers During Training
}

\author{
Authors

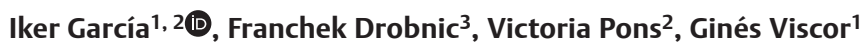

Affiliations

1 Secció de Fisiologia, Departament de Biologia Cel lular, Fisiologia i Immunologia, Facultat de Biologia, Universitat de Barcelona, Barcelona, Spain

2 Departament de Fisiologia i Nutricio, Centre d'Alt Rendiment, Sant Cugat Del Valles, Spain

3 Medical Services, Shenhua Greenland FC, Shanghai, China

Key words

diffusing capacity, lung diffusing capacity for carbon monoxide (DLCO), artistic swimming, synchronized swimming, swimming-induced pulmonary oedema (SIPO)

accepted 19.06.2020

Published online 26.08 .2020

Bibliography

Int J Sports Med 2021; 42: 227-233

DOI $10.1055 / \mathrm{a}-1212-1020$

ISSN $0172-4622$

(c) 2020. Thieme. All rights reserved.

Georg Thieme Verlag KG, Rüdigerstraße 14,

70469 Stuttgart, Germany

\section{Correspondence}

Iker García

Departament de Biologia Cel lular, Fisiologia i Immunologia, Facultat de Biologia, Universitat de Barcelona,

Avinguda Diagonal 643

08007 Barcelona,

Spain

Tel.: 660795805, Fax : 660795805

ikergarciaalday@gmail.com

\begin{abstract}
Artistic swimmers (AS) are exposed to repeated apnoeas in the aquatic environment during high intensity exercise provoking specific physiological responses to training, apnoea, and immersion. This study aimed to evaluate the changes in lung diffusing capacity in AS pre-, mid- and post-training in a combined session of apnoeic swimming, figures and choreography. Eleven elite female AS from the Spanish national team were the study's participants. The single-breath method was used to measure lung diffusing capacity for carbon monoxide ( $\mathrm{DL}_{\mathrm{CO}}$ ) and one-way repeated measures ANOVA was utilized to evaluate the statistical analysis. Basal values of $\mathrm{DL}_{\mathrm{CO}}$ were higher than normal for their age and height $\left(33.6 \pm 4.9 \mathrm{~mL} \cdot \mathrm{min}^{-1} \cdot \mathrm{mmHg}^{-1}\right.$; $139 \pm 19 \%)$ and there were a significant interaction between $\mathrm{DL}_{\mathrm{CO}}$ and $\mathrm{AS}$ training $\left(\mathrm{\eta}_{\mathrm{p}}^{2}=0.547\right)$. After the apnoeic swimming (mid-training) there was an increase in $\mathrm{DL}_{\mathrm{CO}}$ from basal to 36 . $7 \pm 7.3 \mathrm{~mL} \cdot \mathrm{min}^{-1} \cdot \mathrm{mmHg}^{-1}(\mathrm{p}=0.021)$, and after the figures and choreography (post-training) there was a decrease compared to mid-training $\left(32.3 \pm 4.6 \mathrm{~mL} \cdot \mathrm{min}^{-1} \cdot \mathrm{mmHg}^{-1}, \mathrm{p}=0.013\right)$. Lung diffusing capacity changes occur during AS training, including a large increase after apnoeic swimming. There were no differences in lung diffusing capacity from pre- to post-training, although large inter-individual variability was observed.
\end{abstract}

\section{Introduction}

Artistic swimming is an extremely demanding sport which combines swimming, artistic skills, power and flexibility. The artistic swimming routines require precise synchronized movements above and below the water surface thus combining apnoeic and non-apnoeic periods. The competitive routines last 3-4 min and artistic swimmers (AS) may spend $50-65 \%$ of the total time with their faces underwater [1, 2]. Water immersion of the body produces a physiological response known as a diving response [3], which induces changes at cardiovascular and respiratory level, including redistribution of regional blood flow to the body core, peripheral vasoconstriction, increase in arterial blood pressure, and decrease in cardiac output [4]. While AS can hold their breath for a longer time, and have greater lung capacity than control subjects $[5,6]$, to the best of our knowledge, no study has described the lung diffusing capacity presented by AS or the lung functional changes produced during artistic swimming training. 
Artistic swimmers (AS) spend part of their training in regular surface swimming. The swimming respiratory mechanics consist of a rapid out-of-water phase of forced inhalation and a relaxed underwater phase of prolonged exhalation provoking swimmers to establish a "controlled breathing pattern" which must be coordinated with the stroke movements [7]. Swimmers have larger lungs and higher diffusing capacity than other athletes [7]. However, swimming training may provoke a decrease in lung diffusing capacity (unpublished) and it may trigger mechanical stress failure leading to Swimming-induced pulmonary oedema (SIPO) during the practice [8]. This condition is characterized by an extravasation of fluid to the interstitial space caused by a disruption of the capillary-alveolar barrier under high pulmonary arterial pressure and high capillary blood flow in the central circulation [9]. Both physiological conditions are stimulated by swimming exercise, apnoeic periods and immersion, which are some specific characteristics of artistic swimming [10].

The diffusion capacity for carbon monoxide ( $\mathrm{DL}_{\mathrm{CO}}$ ) describes the conductance of gas from the alveolar air to the capillaries and provides a measure of gas transfer in the lungs [11]. A decrease in $\mathrm{DL}_{\mathrm{CO}}$ has been observed after exercise [12-14] although to the best of our knowledge, water-based exercise has not been considered. The reasons for the decrease in lung diffusion are unclear, but the more plausible explanations are the redistribution of central blood volume to peripheral areas [15] and/or the occurrence of a lung interstitial oedema [13].

The question faced by this study is whether recurrent mechanical stress in the lungs during AS training lead to lung function alterations, given the large number of repeated apnoeas that these athletes accomplish during training [16]. Therefore the aim of the study is to describe (i) the parameters presented in lung capacity and diffusion in elite female AS and (ii) the changes provoked by artistic swimming training in the pulmonary alveoli-capillary diffusion measuring $\mathrm{DL}_{\mathrm{CO}}$ and other pulmonary parameters at the middle (after the apnoeic swimming) and at the end of the training session (after the figures and choreography).

\section{Materials and Methods}

\section{Participants}

The participants were 11 international level AS. All of them were members of the Spanish national team. All of them have participated in European and World Championships and some of them have been World and Olympic medallists. They were all female ranged from 16 to 24 years old and they had a training schedule of $40 \mathrm{~h}$ per week. Training routines consisted in water-based artistic skills, swimming training, choreography, stretching sessions, strength training and physical conditioning. The AS participants did not present with any symptoms of respiratory discomfort (cough, wheezing, or shortness of breath) during training.

\section{Anthropometrical and physiological characterization}

At the beginning of the study, a physical evaluation was made to characterize the sample of elite artistic swimmers, including a spirometric test, anthropometrical measurements and an incremental maximal test. Spirometry was performed to calculate lung volumes and flows in accordance with ATS/ERS Guidelines [17]. Anthropometric measurements were obtained by the same experienced technician following the principles of the International Society for the Advancement of Kinanthropometry (ISAK). Skinfold measurement included triceps, subscapular, biceps, suprailiac, abdominal, thigh, and medial calf. The incremental test used to determine maximal oxygen consumption $\left(\mathrm{VO}_{2} \mathrm{max}\right)$ and maximal exercise ventilation $\left(V_{E} \max \right)$ was performed on a cycle ergometer starting at 50 watts (W) and increasing by $25 \mathrm{~W}$ per minute until exhaustion. It must be mentioned that the $\mathrm{VO}_{2}$ max may have been underestimated because the maximum incremental tests were carried out on a cycle ergometer. Some studies have addressed this concern and have shown mixed results. Lobenius et al. [18] found different $\mathrm{VO}_{2}$ max with a $10 \%$ decrease in cycle ergometer versus water-based exercise while Engelmann et al. [19] found a similar $\mathrm{VO}_{2}$ max in both modalities.

\section{Experimental design}

The participants performed two $\mathrm{DL}_{\mathrm{CO}}$ measurements before the start of the study to become familiar with the method. The computerized spirometer used to evaluate lung capacity and diffusion was placed in a room $20 \mathrm{~m}$ away from the pool. On the day of the study, the participants were called 15 min before the beginning of the training to assess their diffusing capacity.

The artistic swimming session lasted for $3 \mathrm{~h}$ including a first part of apnoeic swimming and a second part of figures and choreography ( $\triangleright$ Fig. 1). The apnoeic swimming was composed of $2000 \mathrm{~m}$ of interval swimming at moderate intensity breathing bilaterally every 5,7 or 9 strokes. The main part of the apnoeic swimming was composed of 4 blocks of 6 sets of $60 \mathrm{~m}$ with a recovery period of 30-s between sets and $1 \mathrm{~min}$ between blocks. The participants were instructed to return to the examination room in the first minute after the end of the apnoeic swimming part of the training. After that, the AS spent $2 \mathrm{~h}$ practicing the figures and choreography of their artistic routine, an interval type of training with large apnoeic periods (from 8-s to 24-s) during sets of 90-s to 3 min at maximal intensity and long rest periods between sets ( $3-6 \mathrm{~min})$. At the end of the training, AS performed 3 sets of the whole artistic routine ( $\sim 3 \mathrm{~min})$ at maximal intensity before returning to the examination room to again test their lung diffusing capacity.

An important point of this study was to evaluate $\mathrm{DL}_{\mathrm{CO}}$ as quickly as one minute after the participants had stopped exercising. To achieve this, they came to the examination room one by one while the rest of their teammates kept swimming (in the mid- measure-

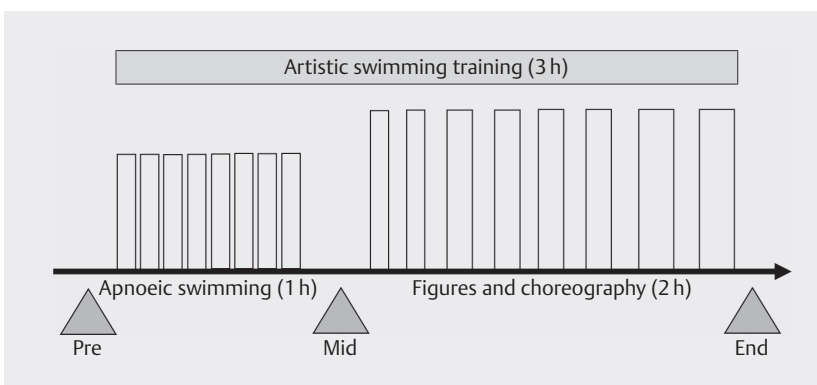

- Fig. 1 Schematic representation of the artistic swimming training session protocol. 
ment) and practising the routine individually (in the post- measurement) until it was their turn to be evaluated. In each condition, the first "grade A" manoeuvre was considered, as identified by the system [17]. If the measure was not considered as "grade A", at least 4 min were allowed to ensure adequate washout of the gases before the repetition of the test. In addition, the haemoglobin ( $\mathrm{Hb})$ concentration was determined from a small blood sample obtained by venepuncture to adjust $\mathrm{DL}_{\mathrm{CO}}$ to individual parameters before the beginning of the training.

\section{Pulmonary function measurements}

The procedure used to obtain lung diffusing capacity $\left(\mathrm{DL}_{\mathrm{CO}}\right)$ parameters was the single-breath method, for which a computerized spirometer (Ganshorn, PowerCube Diffusion + , Niederlauer, Germany) was attached to a gas mixture cylinder to find the diffusing lung capacity of the participants. This method involves measuring the uptake of $\mathrm{CO}$ from the lung over a short breath-holding period to calculate $\mathrm{DL}_{\mathrm{CO}}$. The recommendations made in a recent joint statement by the American Thoracic Society (ATS) and the European Respiratory Society (ERS) were followed [17]. The participants were placed in a seated position, with a mouthpiece and nose-clip in place throughout the test procedure. The test started with tidal breathing for 2-4 breaths until the subject felt comfortable with the mouthpiece. Then the $D L_{C O}$ manoeuvre began with an unforced exhalation to residual volume (RV). At RV the subject's mouthpiece was connected to a source of test gases, and the subject inhaled rapidly to maximal inspiration. After that, the participant was asked to hold their breath for $10 \mathrm{~s}$ and then exhale completely without interruption in less than $4 \mathrm{~s}$ and to continue with a tidal breath to finish the test. The test gases used to calculate pulmonary function and diffusing capacity were $0.3 \%$ of $\mathrm{CO}, 11 \%$ of a tracer inert gas (He) used to measure alveolar volume (VA) and the initial alveolar $\mathrm{CO}$, and a mixture of $20.9 \%$ of $\mathrm{O}_{2}$ balanced with $\mathrm{N}_{2}$. In addition, transfer coefficient of the lung for carbon monoxide $\left(\mathrm{K}_{\mathrm{CO}}\right)$, total lung capacity (TLC), vital capacity inspired (VC $\left.\mathrm{IN}_{\mathrm{IN}}\right)$, and $\mathrm{RV}$ were calculated and the percentage predicted by age and height (\%-predicted) for pulmonary parameters were considered accordingly with the supplementary material from Stanojevic et al. [20].

\section{Ethical considerations}

The study protocol and procedures were approved by the Clinical Research Ethics Committee at the Direcció General de l'Esport of the Catalonian Sports Council. All the participants were informed of the purpose, protocol, and procedures before informed consent was obtained from them or their representatives. The study was carried out according to the Declaration of Helsinki for human experimentation and we confirm that the study meets the journal's ethical standards [21].

\section{Statistical analysis}

Data are reported as mean values \pm standard deviation (SD) [95\% $\mathrm{Cl}$ (confidence interval)]. The Shapiro-Wilk test was used to establish the normal distribution of the sample. Differences in pulmonary parameters between pre-, mid- and post-training conditions were analysed using one-way repeated measures analysis of variance (ANOVA) and, in case of detecting statistical effects $(p<0.05)$, Bonferroni comparisons were performed. Effect sizes as partial eta squared $\left(\eta^{2}\right)$ values were employed to present the magnitude of differences with $0.01,0.06$ and above 0.15 thresholds for the trivial, small, medium and large effects, respectively [22]. Statistical power (sp) was also calculated. The Mauchly's test of sphericity was performed for the effect of the conditions in the $\mathrm{DL}_{\mathrm{CO}}$ values, and if violated $(p<0.05)$, a Greenhouse-Geisser correction was applied. The software package used for the statistical analysis was SPSS v26 (IBM SPSS Statistics).

\section{Results}

\section{Anthropometrical and physiological description}

- Table 1 shows a description of the physical, anthropometric and spirometric characteristics from our sample of 11 elite female artistic swimmers as mean values $\pm \mathrm{SD}[95 \% \mathrm{Cl}$.

\section{Changes in pulmonary function during artistic swimming training}

Changes in lung diffusing capacity and lung volume during AS training are shown in $>$ Table 2 . Basal lung capacity and diffusing capacity of elite artistic swimmers were higher than those predicted by age and height with a large variation inter-subjects, including $D L_{C O}$ $(139 \pm 19 \%), K_{\text {CO }}(109 \pm 14 \%)$ and VA $(125 \pm 7 \%)$.

There was a significant interaction between changes in $\mathrm{DL}_{\mathrm{CO}}$ and AS training, $\left(F_{1.17,11.72}=12.06, p=0.001, \eta^{2}{ }_{p}=0.547, s p=\right.$ 0.916; $>$ Fig. 2). Regarding the comparison by pairs, there was a significant increase in $\mathrm{DL}_{\mathrm{CO}}$ from pre-training to mid-training (33.6 \pm 4.9 to $\left.36.7 \pm 7.3 \mathrm{~mL} \cdot \mathrm{min}^{-1} \cdot \mathrm{mmHg}^{-1}, \mathrm{p}=0.021\right)$, and there was a significant decrease from mid- to post-training ( $36.7 \pm 7.3$ to 32.3 $\left.\pm 4.6 \mathrm{~mL} \cdot \mathrm{min}^{-1} \cdot \mathrm{mmHg}^{-1}, \mathrm{p}=0.013\right)$. However there were no significant differences in $\mathrm{DL}_{\mathrm{CO}}$ from pre-training to post-training (33.6 \pm 4.9 to $32.3 \pm 4.6 \mathrm{~mL} \cdot \mathrm{min}^{-1} \cdot \mathrm{mmHg}^{-1}, \mathrm{p}=0.086$ ).

There was a similar interaction between changes in $\mathrm{K}_{\mathrm{CO}}$ and $\mathrm{AS}$ training $\left(F_{2,20}=11.87, p=0.001, \eta^{2}=0.541, s p=0.986\right.$; Fig. 2$)$. Regarding the multiple comparison by pairs, there was a significant increase in $\mathrm{K}_{\mathrm{CO}}$ from pre-training to mid-training ( $5.14 \pm 0.66$ to $5.51 \pm$

- Table 1 Anthropometrical and physiological description of the elite female artistic swimmers.

\begin{tabular}{|c|c|}
\hline & Artistic swimmers $(n=11)$ \\
\hline Age $(y)$ & $20.3 \pm 3.5[2.0]$ \\
\hline Height (cm) & $170.8 \pm 4.4[2.5]$ \\
\hline Body weight (kg) & $57.5 \pm 6.1[3.5]$ \\
\hline $\mathrm{BMI}\left(\mathrm{kg} \cdot \mathrm{m}^{2}\right)$ & $19.7 \pm 1.7[0.9]$ \\
\hline 6 skinfold $(\mathrm{mm})$ & $74.5 \pm 8.4[4.8]$ \\
\hline $\mathrm{VO}_{2} \max \left(\mathrm{mL} \cdot \mathrm{kg}^{-1} \mathrm{~min}^{-1}\right)$ & $45.9 \pm 4.8[2.6]$ \\
\hline $\mathrm{V}_{\mathrm{E}} \max \left(\mathrm{L} \cdot \mathrm{min}^{-1}\right)$ & $96.5 \pm 20.9[11.4]$ \\
\hline FVC (L) & $4.46 \pm 0.5[0.27]$ \\
\hline FVC (\%-predicted) & $106.9 \pm 10[5.8]$ \\
\hline FEV1 (L) & $3.7 \pm 0.5[0.3]$ \\
\hline FEV1 (\%-predicted) & $104.3 \pm 15[8.8]$ \\
\hline FEV1/FVC & $82.4 \pm 8.9[5.3]$ \\
\hline $\operatorname{PEF}\left(L \cdot \mathrm{S}^{-1}\right)$ & $6.8 \pm 1.3[0.8]$ \\
\hline FEF $25-75\left(L \cdot \mathrm{s}^{-1}\right)$ & $3.6 \pm 1.0[0.6]$ \\
\hline
\end{tabular}


- Table 2 Changes in lung diffusing capacity and lung volume parameters during artistic swimming training from pre-, to mid-, to post-training.

\begin{tabular}{|c|c|c|c|}
\hline & \multicolumn{3}{|c|}{ Artistic swimmers $(n=11)$} \\
\hline & Pre & Mid & Post \\
\hline $\mathrm{DL}_{\mathrm{CO}}\left(\mathrm{mL} \cdot \mathrm{min}^{-1} \cdot \mathrm{mmHg}^{-1}\right)$ & $33.6 \pm 4.9[2.7]$ & $36.7 \pm 7.3[4.3]^{\mathrm{a}}$ & $32.3 \pm 4.6[2.5]^{\mathrm{b}}$ \\
\hline $\mathrm{DL}_{\mathrm{CO}}(\%$-predicted $)$ & $139 \pm 19[9]$ & $152 \pm 29[15]$ & $135 \pm 17[9]$ \\
\hline $\mathrm{K}_{\mathrm{CO}}\left(\mathrm{mL} \cdot \mathrm{min}^{-1} \cdot \mathrm{mmHg}^{-1} \cdot \mathrm{L}^{-1}\right)$ & $5.14 \pm 0.66[0.39]$ & $5.51 \pm 0.91[0.54]^{\mathrm{a}}$ & $4.89 \pm 0.64[0.38]^{\mathrm{b}}$ \\
\hline $\mathrm{K}_{\mathrm{CO}}(\%$-predicted $)$ & $109 \pm 14[8]$ & $116 \pm 19[11]$ & $105 \pm 13[8]$ \\
\hline VA (L) & $6.43 \pm 0.44[0.26]$ & $6.62 \pm 0.50[0.29]$ & $6.51 \pm 0.50[0.30]$ \\
\hline VA (\%-predicted) & $125 \pm 7[4]$ & $128 \pm 9[6]$ & $126 \pm 9[5]$ \\
\hline $\operatorname{TLC}(\mathrm{L})$ & $6.56 \pm 0.43[0.26]$ & $6.74 \pm 0.51[0.30]$ & $6.64 \pm 0.51[0.30]$ \\
\hline TLC (\%-predicted) & $123 \pm 11[7]$ & $129 \pm 11[6]$ & $124 \pm 14[8]$ \\
\hline $\mathrm{VC}_{\mathrm{IN}}(\mathrm{L})$ & $4.96 \pm 0.32[0.19]$ & $4.91 \pm 0.42[0.25]$ & $4.98 \pm 0.46[0.27]$ \\
\hline $\mathrm{VC}_{\mathrm{IN}}$ (\%-predicted) & $129 \pm 10[6]$ & $125 \pm 11[7]$ & $127 \pm 11[7]$ \\
\hline $\mathrm{RV}(\mathrm{L})$ & $1.60 \pm 0.33[0.19]$ & $1.84 \pm 0.35[0.21]^{\mathrm{a}}$ & $1.65 \pm 0.27[0.16]^{\mathrm{b}}$ \\
\hline RV (\%-predicted) & $119 \pm 26[15]$ & $138 \pm 31[18]$ & $124 \pm 24[14]$ \\
\hline
\end{tabular}

$\left.0.91 \mathrm{~mL} \cdot \mathrm{min}^{-1} \cdot \mathrm{mmHg}^{-1} \cdot \mathrm{L}^{-1}, \mathrm{p}=0.034\right)$, and there was a significant decrease from mid- to post-training ( $5.51 \pm 0.91$ to $4.89 \pm 0.6$ $\left.4 \mathrm{~mL} \cdot \mathrm{min}^{-1} \cdot \mathrm{mmHg}^{-1} \cdot \mathrm{L}^{-1}, \mathrm{p}=0.008\right)$. Also, there were no significant differences in $\mathrm{K}_{\mathrm{CO}}$ from pre-training to post-training $(5.14 \pm$ 0.66 to $\left.4.89 \pm 0.64 \mathrm{~mL} \cdot \mathrm{min}^{-1} \cdot \mathrm{mmHg}^{-1} \cdot \mathrm{L}^{-1}, \mathrm{p}=0.069\right)$.

Regarding lung volumes parameters, there were no changes during AS training in VA ( $p=0.167)$, TLC $(p=0.169)$, and $V C_{I N}$ $(p=0.700)$. Lastly, there was a significant interaction between changes in RV and AS training $\left(F_{2,20}=10.50, p=0.001, \eta^{2}{ }_{p}=0.512\right.$, $\mathrm{sp}=0.974)$. Regarding the multiple comparison by pairs, there was a significant increase in RV from pre-training to mid-training $(1.60 \pm 0.33$ to $1.84 \pm 0.35 \mathrm{~L}, \mathrm{p}=0.010)$, and a significant decrease from mid- to post-training $(1.84 \pm 0.35$ to $1.65 \pm 0.27 \mathrm{~L}, \mathrm{p}=0.008)$, but there was no significant differences from pre-training to posttraining ( $1.60 \pm 0.33$ to $1.65 \pm 0.27 \mathrm{~L}, \mathrm{p}=1.000)$.

\section{Discussion}

Artistic swimmers (AS) presented higher values in pulmonary function compared to the reference values for their age and height. Changes in $\mathrm{DL}_{\mathrm{CO}}$ occur during $\mathrm{AS}$ training, including a large increase after apnoeic swimming in the middle of the training and a decrease after figures and choreography at the end of the training. However, there were no significant differences in lung diffusing capacity from pre- to post-training, although large inter-individual variability was found.

Lungs are involved in oxygen delivery during activities with apnoeic periods such as artistic swimming. However, to the best of our knowledge only two studies have analysed some physiological data of lung capacity in AS showing that they can hold their breath for a longer time, and they have greater vital capacity (VC), total lung capacity (TLC), forced expiratory volume (FEV) and forced expiratory volume in one second (FEV1) than the general population $[5,6]$. When comparing our results with the pulmonary evaluation made by Roby et al. [23] in 1983 with Olympic champions from the US, some differences can be described. Our sample shows higher $\mathrm{DL}_{\mathrm{CO}}$ and $\mathrm{VA}$, but lower $\mathrm{K}_{\mathrm{CO}}$ than the leading world $\mathrm{AS}$ from that time. This is probably because AS now train their physical capacities harder than they did in the 1980s.

The singular training challenges faced by AS can be summarized as a high metabolic demand with recurrent apnoeic periods within the aquatic environment which provoke a bradycardic response and blunted hypoxic ventilatory response (HVR) [24]. This condition may stress the respiratory system via lung hyperinflated manoeuvres, hypoxemia [25], and mechanical loading [5]. Although land-based sports have not been associated with lung growth, hypoxia or mechanical strain may stimulate lung growth [26]. Hence the exposure to repeated apnoeas in a water-based environment could be the reason why swimmers [7], apnoeic divers [27], and artistic swimmers [6] had larger lung capacity and diffusion than land-based athletes. A longitudinal study must still be performed to evaluate whether these differences are because of swimming training or genetic influence.

In our study, apnoeic swimming training increased lung diffusing capacity compared to pre-training ( $+9.2 \%)$. This type of training demands a high metabolic rate combined with relatively short apnoeic periods (5-s to 12-s) which require low respiratory frequency and high tidal volume, a breathing pattern that involves high inspiratory muscle strength [28]. As cardiac output (Q) increases to meet $\mathrm{O}_{2}$ delivery requirements during exercise, the increase in right ventricular pressure results in an increase in pulmonary arterial pressure (PAP), which in turn provokes a recruitment and distension of the pulmonary capillaries [29] increasing alveolar-capillary surface area available for gas exchange [30,31]. The increase in $\mathrm{DL}_{\mathrm{CO}}$ during exercise has been attributed to an increase in pulmonary capillary blood volume $(\mathrm{Vc})$ and a better matching between tissue and erythrocyte surfaces, rather than an increase in $D_{M}$ [32]. However, the greater $\mathrm{DL}_{\mathrm{CO}}$ improvement found in endurance athletes compared to non-athletes has also been associated with the increase in membrane diffusing capacity $\left(D_{M}\right)[29]$ suggesting that endurance athletes have a better response in alveolar-capillary membrane that facilitates the transfer of $\mathrm{O}_{2}$ during exercise which may be in accordance with the increase of $\mathrm{K}_{\mathrm{CO}}$ in AS after the apnoeic swimming training. 

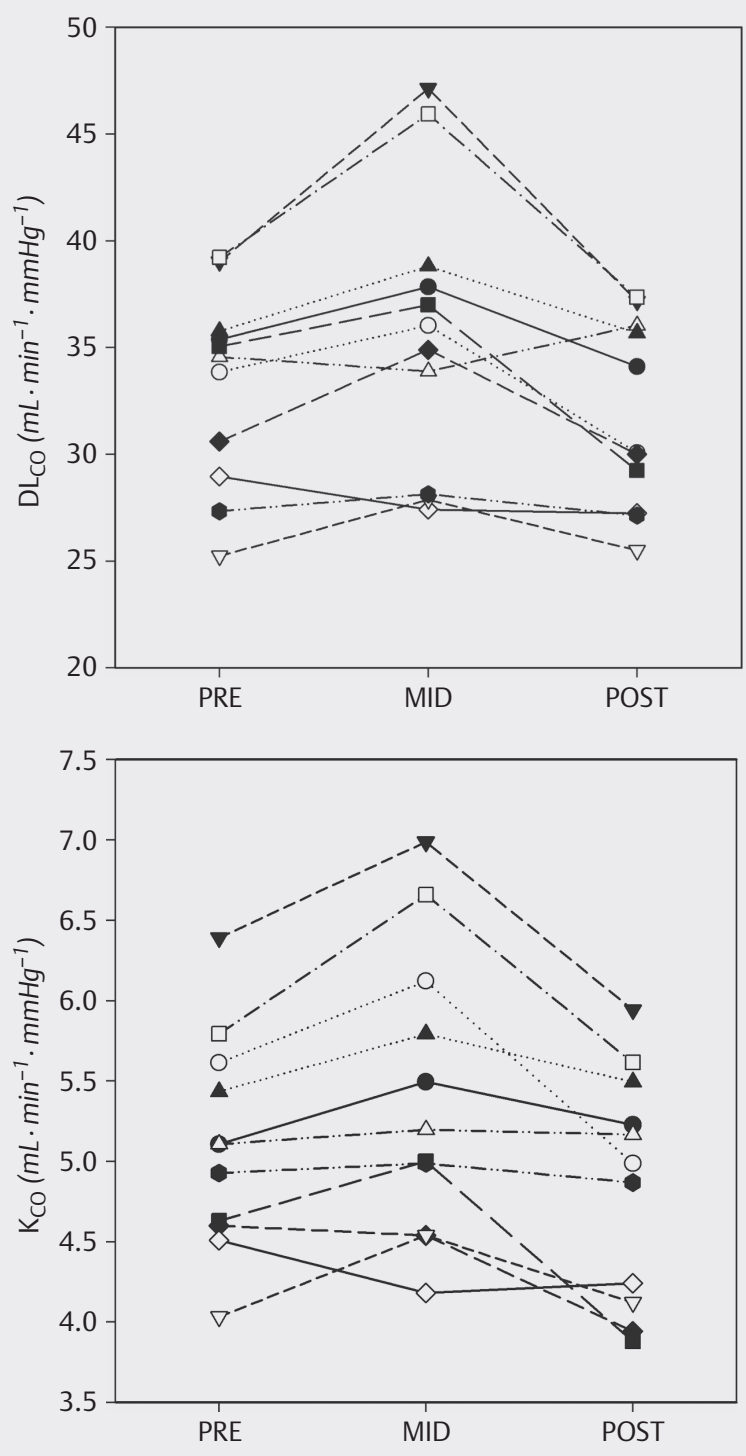

- Fig. 2 Changes in lung diffusing capacity ( $\mathrm{DL}_{\mathrm{CO}}$ and $\mathrm{K}_{\mathrm{CO}}$ ) from pre-, to mid-, to end of the training in female elite artistic swimmers.

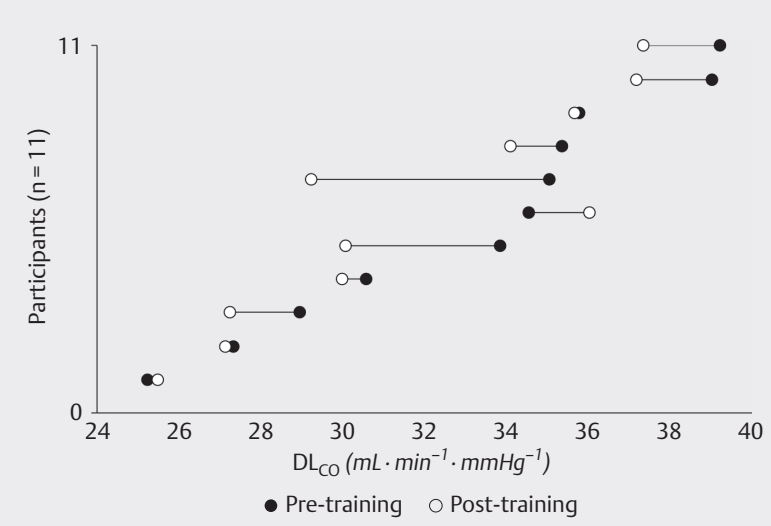

- Fig. 3 Intra-individual changes in $\mathrm{DL}_{\mathrm{CO}}$ from pre-training to posttraining in each one of the 11 artistic swimmers.
Later, the figures and choreography training provoked a decrease in $\mathrm{DL}_{\mathrm{CO}}$ from mid- to post-training $(-13.6 \%)$, but no differences were found from pre- to post-training. This type of training is characterized by high intensity bouts of exercise with large apnoeic periods (8-s to 24-s) and long rest periods. The results are inconclusive since a slight, but no significant decrease $(-4.0 \%)$ is appreciated, and 9 of $11 \mathrm{AS}$ had a decrease in $\mathrm{DL}_{\mathrm{CO}}$ and $\mathrm{K}_{\mathrm{CO}}$ after training. Also, a large inter-individual variability is presented ( $\bullet$ Fig. $\mathbf{3}$ ), including $5 \mathrm{AS}$ with a large decrease in $\mathrm{DL}_{\mathrm{CO}}$ after training ( -5 to $-20 \%), 4$ AS with small decrease after training ( -0.7 to $-3.7 \%)$ and $2 \mathrm{AS}$ with a small increase after training ( +1.1 to $+4.1 \%)$.

The literature is consistent regarding the decrease in $\mathrm{DL}_{\mathrm{CO}}$ after training in land-based exercise [12-14,33], and we have found similar results in swimmers after training with a consistent and significant decrease $(-2.5 \%)$ in a large population of 21 participants along 207 pre- to post-training evaluations (under revision). The first possible explanation of this decrease is the redistribution of the blood flow to the peripheral tissues after the training through a reduction in central and pulmonary blood volume after exercise [34], and a significant redistribution of fluid shift from the thorax to the peripheral vascular space [15]. However, we measure $D_{c o}$ just one minute after exercise, and we showed a slight, but not significant increase in VA and TLC after swimming ( $\triangleright$ Table 2 ). This suggests higher capillary recruitment in the lungs post- training compared to pre-training and evidences the inconsistency of this hypothesis in our case. The second possible explanation of this decrease in $\mathrm{DL}_{\mathrm{CO}}$ is swimming-induced pulmonary oedema (SIPO), in which extravasation of fluid to the lung extravascular space is produced under a condition of high capillary flow and pressure $[9,35]$. Besides, SIPO could occur in a subclinical manner since AS present some predisposing risk factors such as exercise, hypoxic exposure and immersion [10].

\section{Limitations}

In the literature, some AS have complained of cough, dizziness, and even momentary black-out $[2,36]$ suggesting undesirable levels of hypoxia, hypersensitivity to chlorine, or a respiratory condition. In addition, the respiratory redox-state of swimmers can be affected by chronic exposures to chlorinated pools, to a greater extent than land-based athletes [37]. None of the athletes enrolled in this study suffered from asthma or allergy, nor did they present signs or symptoms of bronchial hyperreactivity associated with the practice of their sport. All of them showed baseline functional tests within the normal range. For this reason, it was not considered necessary to perform tests for bronchial reactivity, bronchodilator, methacholine, cold air or voluntary isocapnic hyperventilation. However, we do not know whether, even without showing the symptoms associated with exposure to chlorine derivatives, any of them could be hyperreactive [38].

To the best of our knowledge, this is the first study that evaluate pulmonary function in relation to AS training, although we did not measure either $D_{M}$ or $V_{c}$ that would have provided a deeper explanation of the changes in lung diffusing capacity [39]. Further studies should contemplate the inter-individual response to AS training in lung diffusing capacity in combination with direct techniques, such as imaging techniques, that would be the most suit- 
able approach for demonstrating the presence of a mild perturbation in extravascular fluid balance [40].

\section{Conclusion}

In summary, lung diffusing capacity changes occur during AS training, including a large increase after apnoeic swimming in the middle of the training. Regarding the pre- vs post- comparison, there were no significant differences, but it could be interesting to monitor individual cases since large variability can be appreciated, including some AS with a large decrease in lung diffusing capacity after the routines and choreography. However, artistic swimmers show larger lungs and higher diffusing capacity than reference values. Therefore, the decrease in $\mathrm{DL}_{\mathrm{CO}}$ after training, in the case of representing a real physiological detriment, does not lead to a clinical impairment of the alveolar-capillary function.

\section{Acknowledgement}

The authors would like to thank all participants for their time and commitment in undertaking this study and the coach from the Royal Spanish Swimming Federation, Mayuko Fujiki, for the collaboration during the study. Also we would like to thank Gashorn Medical Technologies for the collaboration lending us the technical equipment to develop the study. We are grateful to Dr. Christopher Evans from the SAL (Servei d'Assessorament Lingüístic) of the University of Barcelona and Mrs. Lynette Stewart for his help with editing the text.

\section{Conflict of Interest}

The authors declare that they have no conflict of interest.

\section{References}

[1] Alentejano T, Marshall D, Bell G. A time-motion analysis of elite solo synchronized swimming. Int J Sports Physiol Perform 2008; 3: 31-40

[2] Davies BN, Donaldson GC, Joels N. Do the competition rules of synchronized swimming encourage undesirable levels of hypoxia? $\mathrm{Br}$ J Sports Med 1995; 29: 16-19

[3] Schagatay E, Van Kampen M, Emanuelsson S et al. Effects of physical and apnea training on apneic time and the diving response in humans. Eur J Appl Physiol 2000; 82: 161-169

[4] Ferretti G, Costa M. Diversity in and adaptation to breath-hold diving in humans. Comp Biochem Physiol A Mol Integr Physiol 2003; 136: 205-213

[5] Alentejano TC, Marshall D, Bell G]. Breath holding with water immersion in synchronized swimmers and untrained women. Res Sports Med 2010; 18: 97-114

[6] Bjurstrom RL, Schoene RB. Control of ventilation in elite synchronized swimmers. J Appl Physiol (1985) 1987; 63: 1019-1024

[7] Mickleborough TD, Stager JM, Chatham K et al. Pulmonary adaptations to swim and inspiratory muscle training. Eur J Appl Physiol 2008; 103 : 635-646

[8] Hohmann E, Glatt V, Tetsworth K. Swimming induced pulmonary oedema in athletes - a systematic review and best evidence synthesis. BMC Sports Sci Med Rehabil 2018; 10: 18
[9] Shupak A, Weiler-Ravell D, Adir Y et al. Pulmonary oedema induced by strenuous swimming: A field study. Respir Physiol 2000; 121: 25-31

[10] Marabotti C, Cialoni D, Pingitore A. Environment-induced pulmonary oedema in healthy individuals. Lancet Respir Med 2017; 5: 374-376

[11] Hegewald MJ. Diffusing capacity. Clin Rev Allergy Immunol 2009; 37: 159-166

[12] Baldi JC, Dacey MJ, Lee M] et al. Prior maximal exercise decreases pulmonary diffusing capacity during subsequent exercise. Int J Sports Med 2014; 35: 982-986

[13] Johns DP, Berry D, Maskrey M et al. Decreased lung capillary blood volume post-exercise is compensated by increased membrane diffusing capacity. Eur J Appl Physiol 2004; 93: 96-101

[14] Sheel AW, Coutts KD, Potts JE et al. The time course of pulmonary diffusing capacity for carbon monoxide following short duration high intensity exercise. Respir Physiol 1998; 111: 271-281

[15] Hanel B, Teunissen I, Rabøl A et al. Restricted postexercise pulmonary diffusion capacity and central blood volume depletion. J Appl Physiol (1985) 1997; 83: 11-17

[16] Mijacika T, Dujic Z. Sports-related lung injury during breath-hold diving. Eur Respir Rev 2016; 25: 506-512

[17] Graham BL, Brusasco V, Burgos F et al. 2017 ERS/ATS standards for single-breath carbon monoxide uptake in the lung. Eur Respir J 2017; 49: 1600016

[18] Lobenius K. Physiological differences during exercise in water and on cycle ergometer for synchronised swimmers. In: Chatard J-C Ed. Biomechanics and Medicine in Swimming IX. Saint-Étienne: University of Saint-Étienne; 2002: 539-544

[19] Engelmann LI, Liedtke GV, de Souza Castro F. Oxygen uptake in water polo, comparison and agreement in cycle ergometer and eggbeater kick: A pilot study. Motriz J Phys Ed 2016; 22: 211-216

[20] Stanojevic S, Graham BL, Cooper BG et al. Official ERS technical standards: Global Lung Function Initiative reference values for the carbon monoxide transfer factor for Caucasians. Eur Respir J 2017; 50: 1700010

[21] Harriss D], Macsween A, Atkinson G. Ethical standards in sport and exercise science research: 2020 update. Int J Sports Med 2019; 40: 813-817

[22] Cohen J. Statistical Power Analysis for the Behavioral Sciences (2nd ed). Hillsdale, NJ: Lawrence Earlbaum Associates; 1988

[23] Roby FB, Buono M], Constable SH. Physiological characteristics of champion synchronized swimmers. Phys Sportsmed 1983; 11: 136-147

[24] Viana E, Bentley DJ, Logan-Sprenger HM. A Physiological overview of the demands, characteristics, and adaptations of highly trained artistic swimmers: A literature review. Sport Med Open 2019; 5: 16

[25] Masuda Y, Yoshida A, Hayashi F et al. The ventilatory responses to hypoxia and hypercapnia in the Ama. Jpn J Physiol 1981; 31: 187-197

[26] Wagner PD. Why doesn't exercise grow the lungs when other factors do? Exerc Sport Sci Rev 2005; 33: 3-8

[27] Schagatay E, Richardson MX, Lodin-Sundström A. Size matters: Spleen and lung volumes predict performance in human apneic divers. Front Physiol 2012; 3: 173

[28] Leahy MG, Summers MN, Peters CM et al. The mechanics of breathing during swimming. Med Sci Sports Exerc 2019; 51: 1467-1476

[29] Tedjasaputra V, Bouwsema MM, Stickland MK. Effect of aerobic fitness on capillary blood volume and diffusing membrane capacity responses to exercise. J Physiol 2016; 594: 4359-4370

[30] Hsia CCW. Recruitment of lung diffusing capacity. Chest 2002; 122: 1774-1783

[31] Jorgenson CC, Coffman KE, Johnson BD. Effects of intrathoracic pressure, inhalation time, and breath hold time on lung diffusing capacity. Respir Physiol Neurobiol 2018; 258: 69-75 
[32] Zavorsky GS, Hsia CCW, Hughes JMB et al. Standardisation and application of the single-breath determination of nitric oxide uptake in the lung. Eur Respir ] 2017; 49:1600962

[33] McKenzie DC, Lama IL, Potts JE et al. The effect of repeat exercise on pulmonary diffusing capacity and EIH in trained athletes. Med Sci Sports Exerc 1999; 31: 99-104

[34] Hanel B, Clifford PS, Secher NH. Restricted postexercise pulmonary diffusion capacity does not impair maximal transport for O2. J Appl Physiol (1985) 1994; 77: 2408-2412

[35] Snyder EM, Beck KC, Hulsebus ML et al. Short-term hypoxic exposure at rest and during exercise reduces lung water in healthy humans. J Appl Physiol (1985) 2006; 101: 1623-1632

[36] Mountjoy M. The basics of synchronized swimming and its injuries. Clin Sports Med 1999; 18: 321-336
[37] Araneda OF, Contreras-Briceño F, Cavada G et al. Swimming versus running: effects on exhaled breath condensate pro-oxidants and $\mathrm{pH}$. Eur J Appl Physiol 2018; 118: 2319-2329

[38] Carlsen KH, Anderson SD, Bjermer L et al. Exercise-induced asthma , respiratory and allergic disorders in elite athletes: Epidemiology, mechanisms and diagnosis: Part I of the report from the Joint Task Force of the European Respiratory Society (ERS) and the European Academy of Allergy and Clinic. Allergy 2008; 63: 387-403

[39] Manier G, Moinard J, Stoicheff H. Pulmonary diffusing capacity after maximal exercise. J Appl Physiol (1985) 1993; 2580-2585

[40] Cogo A, Miserocchi G. Pro: Most climbers develop subclinical pulmonary interstitial edema. High Alt Med Biol 2011; 12: 121-124 